\title{
Fine sediment reduces vertical migrations of Gammarus pulex (Crustacea: Amphipoda) in response to surface water loss
}

\author{
Atish N. Vadher $\cdot$ Rachel Stubbington • \\ Paul J. Wood
}

Received: 26 July 2014 / Revised: 28 December 2014/ Accepted: 22 January 2015/Published online: 7 February 2015

(C) The Author(s) 2015. This article is published with open access at Springerlink.com

\begin{abstract}
Surface and subsurface sediments in river ecosystems are recognized as refuges that may promote invertebrate survival during disturbances such as floods and streambed drying. Refuge use is spatiotemporally variable, with environmental factors including substrate composition, in particular the proportion of fine sediment (FS), affecting the ability of organisms to move through interstitial spaces. We conducted a laboratory experiment to examine the effects of FS on the movement of Gammarus pulex Linnaeus (Crustacea: Amphipoda) into subsurface sediments in response to surface water loss. We hypothesized that increasing volumes of FS would impede and ultimately prevent individuals from migrating into the sediments. To test this hypothesis, the proportion of FS (1-2 mm diameter) present within an open gravel matrix (4-16 mm diameter) was varied from 10 to $20 \%$ by volume in $2.5 \%$ increments. Under control conditions ( $0 \%$ FS), $93 \%$ of individuals moved into subsurface sediments as the
\end{abstract}

Handling editor: Beat Oertli

A. N. Vadher · P. J. Wood

Centre for Hydrological and Ecosystem Science,

Department of Geography, Loughborough University, Loughborough, Leicestershire LE11 3TU, UK

\section{R. Stubbington $(\square)$}

School of Science and Technology, Nottingham Trent University, Clifton Campus, Nottingham NG11 8NS, UK

e-mail: rachel.stubbington@ntu.ac.uk water level was reduced. The proportion of individuals moving into the subsurface decreased to $74 \%$ at $10 \%$ FS, and at $20 \%$ FS no individuals entered the sediments, supporting our hypothesis. These results demonstrate the importance of reducing FS inputs into river ecosystems and restoring FS-clogged riverbeds, to promote refuge use during increasingly common instream disturbances.

Keywords Substrate composition - Colmation · Benthic invertebrates · Dewatering · Sedimentation . Hyporheic zone

\section{Introduction}

The bed sediments of river ecosystems are recognized as an important habitat and refuge for benthic macroinvertebrates during adverse conditions in the surface stream (Williams \& Hynes, 1974; Stubbington, 2012). Vertical migrations into the sediments allow mobile taxa to avoid direct exposure to disturbances at both extremes of the hydrological continuum, with some studies recording higher abundances of benthic invertebrates in the hyporheic zone after floods (Williams \& Hynes, 1974; Dole-Olivier et al., 1997) and during streambed drying (Delucchi, 1989; Clinton et al., 1996). The availability of surficial benthic and subsurface hyporheic sediments may therefore promote population and community recovery after a disturbance event (i.e. resilience). However, evidence supporting 
the proposed role of the hyporheic zone as an invertebrate refuge is equivocal, with many studies reporting no vertical migrations during floods (Boulton et al., 2004; Olsen and Townsend, 2005), low flows (James et al., 2008; Young et al., 2011) or streambed drying (Stanley et al., 1994; Belaidi et al., 2004). In addition, many studies have reported significantly greater invertebrate abundance and diversity in benthic compared to hyporheic sediments during disturbances such as severe flow reductions (James et al., 2008), while other studies have indicated that invertebrates may not even migrate into surficial sediments when a streambed dries (Extence, 1981).

This contrasting evidence demonstrates that bed sediments are a patchy refuge (Dole-Olivier et al., 1997), with environmental conditions including hydrological exchange, dissolved oxygen availability and sediment composition determining their potential for invertebrate use and persistence (Stubbington, 2012). In particular, the occurrence of fine sediment within substrate interstices may reduce invertebrate density and diversity (Angradi, 1999; Matthaei et al., 2006) and limit invertebrate movement into and use of subsurface sediments (Navel et al., 2010; Descloux et al., 2013). Substrate size, porosity and permeability evidently influence faunal movements through interstitial spaces (Fowler \& Death, 2001; Descloux et al., 2013), and where invertebrates are unable to enter interstices, they become stranded on the riverbed and may be exposed to adverse conditions such as emersion during streambed drying (Perry \& Perry, 1986; Stubbington et al., 2009).

Fine sediment is typically defined as comprising particles $<2 \mathrm{~mm}$ in diameter (Wood \& Armitage, 1997). The extent of fine sediment deposition within river ecosystems has been greatly increased by anthropogenic activities including agriculture (Nerbonne \& Vondracek, 2001), mining (Byrne et al., 2012) and flow regulation (Sear, 1995), and is considered a major cause of freshwater ecosystem degradation (Jones et al., 2012). Fine sediment clogs subsurface interstices (Brunke, 1999), forming a physical barrier within the benthic and/or hyporheic zones that impedes hydrological exchange and the vertical and lateral movements of invertebrates through interstitial spaces. Previous experimental studies have indicated that increasing volumes of fine sediment reduce invertebrate movements including vertical migrations (Navel et al., 2010; Descloux et al.,
2013). However, the thresholds at which fine sediment reduces or prevents faunal movements through interstices have proved difficult to quantify, due to the heterogeneous nature of river sediments. In addition, the effects of fine sediment on biotic responses to instream disturbances such as streambed drying have not been tested experimentally.

Gammarus pulex Linnaeus (Crustacea: Amphipoda) is a highly mobile, predominantly benthic species that may occur at high abundance in the sediments of temperate-zone streams (Crane, 1994; Stubbington et al., 2011). G. pulex plays important roles in lotic ecosystems, including the processing of coarse particulate organic matter (Kelly et al., 2002; Navel et al., 2010) and the provision of prey for fish (MacNeil et al., 1997). G. pulex has been demonstrated to move from the benthic zone into deeper sediments to avoid predation (McGrath et al., 2007) and field evidence indicates that this taxon actively uses the subsurface sediments during adverse conditions in surface streams (Wood et al., 2010; Stubbington et al., 2011).

We used a laboratory mesocosm facility to examine the effects of an increasing fine sediment volume on the ability of $G$. pulex to migrate into subsurface sediments in response to surface water loss. We used surface water loss as an extreme stressor to trigger vertical migrations, as aquatic organisms that lack adaptations to limit water loss will perish when exposed to air. We hypothesized that increasing the volume of fine sediment within an open gravel matrix would progressively fill interstitial spaces in the surface and subsurface sediments, impeding and ultimately preventing $G$. pulex from moving into the substrate. We aimed to establish the thresholds at which fine sediment reduced and then prevented movement of adult $G$. pulex into the bed, for the gravel size range used. This knowledge will inform river management and restoration initiatives seeking to promote community resilience to disturbance events through the provision of instream refuges.

\section{Materials and methods}

\section{Test organisms}

The freshwater shrimp G. pulex was selected as an ecologically significant test organism for the reasons outlined above. In addition, the relatively large size of 
adults means that they can be readily observed in situ, and a population of $G$. pulex can be maintained in laboratory conditions for extended periods (McGrath et al., 2007). The taxon is therefore both a logistically and ecologically appropriate test organism in experimental work addressing questions of refuge use.

A mixed-gender population of 500 adult G. pulex was obtained from a commercial supplier, supplemented by individuals from a local stream (Burleigh Brook, Loughborough, UK) in which G. pulex is the only amphipod present and occurs at high densities $\left(>500\right.$ individuals $\mathrm{m}^{-2}$ ). Individuals were within the size range 5-12 $\mathrm{mm}$, typically $5-7 \mathrm{~mm}$ for females and $10-12 \mathrm{~mm}$ for males, with a mean head width (based on a standard measurement from the base of the antennae to the rear margin of the head carapace) of $1.43 \pm 0.013 \mathrm{~mm}(n=100)$. Stock populations of test organisms were kept in three 10-1 containers of continuously oxygenated, dechlorinated tap water and fed with an excess of pre-conditioned, mixed-species, native leaf litter.

Development of the mesocosm facility and preliminary trials

The experiment was conducted using a mesocosm facility consisting of a 300-1 capacity experimental tank $(219 \mathrm{~cm} \times 56 \mathrm{~cm} \times 56 \mathrm{~cm})$, a $182-1$ capacity sump tank and a water cooler (Fig. 1). The experimental tank, sump tank and water cooler were connected to form a closed recirculating system in which water flowing into the experimental tank was maintained between 15 and $16^{\circ} \mathrm{C}$ (Fig. 1). Five chambers (i.e. the mesocosms, each $20 \mathrm{~cm} \times 20 \mathrm{~cm} \times 20 \mathrm{~cm} ; 8,000 \mathrm{~cm}^{3}$ ), each made from $3 \mathrm{~mm}$ aperture steel mesh, lined with a $<1 \mathrm{~mm}$ mesh bag and containing $8.2 \mathrm{~kg}$ of fluvial gravel (4.8 $\mathrm{kg}$ of $4-8 \mathrm{~mm}$ diameter and $3.4 \mathrm{~kg}$ of $8-16 \mathrm{~mm}$ diameter particles), were placed side-by-side on a levelled gravel base within the experimental tank (Fig. 1). This gravel size range was selected following preliminary tests, as it facilitated direct observation of G. pulex on and between sediment particles: $>90 \%$ of individuals remained clearly visible during preliminary trials in which water depth was held constant, while gravel particles $>16 \mathrm{~mm}$ in diameter resulted in more individuals being obscured between and under individual particles.

Gravel was washed to remove any fine material, and then was used to fill each chamber to a depth of
$120 \mathrm{~mm}$, with the chamber sides extending $80 \mathrm{~mm}$ above the gravel surface. At the start of each experimental trial, water depth was set to $60 \mathrm{~mm}$ above the sediment surface, with the remaining $20 \mathrm{~mm}$ protruding above the water surface to prevent the escape of test organisms (Fig. 1).

To create treatments with different proportions of fine sediment (FS), 1-2 mm diameter FS was applied to the gravel surface. This sediment size encompasses the size range reported to have the greatest potential to result in interstitial clogging (Weigelhofer \& Waringer, 2003). The average quantity of FS needed to fill the interstices in 1,000 $\mathrm{g}$ of gravel was calculated as $616.7 \mathrm{~g}$ by gradually increasing the FS volume in the gravel matrix. The quantities required to create 10 , $12.5,15,17.5$ and $20 \%$ FS treatments in $8.2 \mathrm{~kg}$ of gravel (i.e. in each chamber) were therefore 505, 632, 758,884 and $1,010 \mathrm{~g}$, respectively. To create an individual FS treatment, the required quantity of FS was applied to the surface of each of the five chambers and 81 of water was passed through the sediments to ensure the FS infiltrated into the gravel matrix. Gravel was washed between trials for individual sediment treatments, to remove any accumulating waste substances and to ensure that the substrate surface was randomized for each trial, therefore preventing organisms from using identical routes multiple times.

Preliminary observations of G. pulex following their placement within chambers indicated that when water depth was kept constant at $60 \mathrm{~mm}$, swimming in the water column, movement over the substrate surface and shelter-seeking behaviour subsided within 5 min. Preliminary trials also demonstrated that a higher proportion of $G$. pulex actively migrated into the subsurface (burrowing with vigorous movement) when water depth was reduced from 60 to $0 \mathrm{~mm}$ $(93 \pm 1.7 \%)$ compared to trials in which depth was held constant at $60 \mathrm{~mm}(6 \pm 0.4 \%$; one-way ANOVA, $P<0.05$ ). Additional preliminary trials to determine an appropriate rate of surface water drawdown indicated no statistical difference between responses over 2 or $6 \mathrm{~h}$ (one-way ANOVA, $P>0.05)$; as a result, the former rate was used.

\section{Trial procedure}

Twelve hours prior to the start of a trial, chambers containing an open gravel matrix were placed in the tank and water recirculated through the system, to 


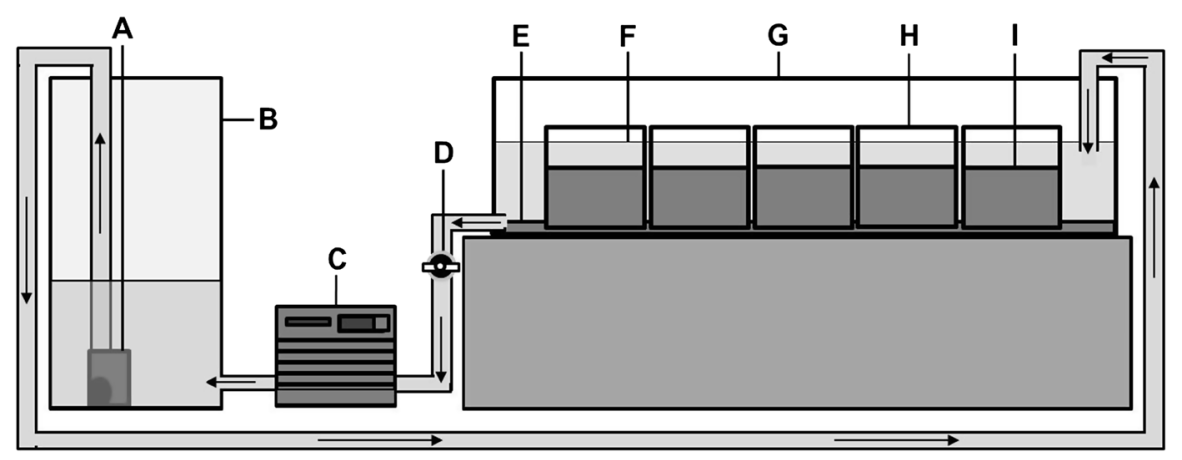

Fig. 1 Schematic cross-section through the experimental apparatus. $A$ water pump, $B$ sump tank, $C$ water cooler, $D$ ball valve used to drain water, $E$ gravel base, $F$ water level $(60 \mathrm{~mm}$

allow the water temperature to reach $15^{\circ} \mathrm{C}$. Flow was then stopped to ensure hydrological conditions were comparable in all chambers, and a FS treatment was applied to each of the five chambers, as described above. Trials for the different sediment treatments were conducted in a randomized order: $0,20,10,15$, 17.5 then $12.5 \%$. All five chambers were treated in an identical manner and three trials (repeated measures) were conducted per sediment treatment.

For each trial, 100 individuals were randomly collected from one of the three 10-1 containers holding the stock populations and transferred to the laboratory $24 \mathrm{~h}$ prior to a trial commencing, to acclimatize to the light and temperature regimes. The container used was rotated so that no individuals were used in successive trials and each individual was used only once per sediment treatment. Twenty G. pulex were placed into each of the five chambers, equating to a population density of 500 individuals $\mathrm{m}^{-2}$, which is comparable with known field densities (Mortensen, 1982; Stubbington et al., 2011). Based on the described results of preliminary trials, test organisms were given a 5-min acclimation period prior to the start of each trial.

During each trial, surface water depth was reduced by $5 \mathrm{~mm}$ every $10 \mathrm{~min}$ for $2 \mathrm{~h}$, from a maximum depth of 60 to $0 \mathrm{~mm}$ i.e. the sediment surface. The number of G. pulex observed above or between gravel particles in each chamber was recorded every 10 min during the $2 \mathrm{~h}$ drawdown period; those not observed were assumed to have moved into subsurface sediments. Following the end of the drawdown period, any individuals on the substrate surface were removed after it became clear that they were stranded and unable to move into the interstices. The water level above gravel matrix), $G$ experimental tank $(219 \mathrm{~cm} \times 56 \mathrm{~cm} \times$ $56 \mathrm{~cm}), H$ chamber $(20 \mathrm{~cm} \times 20 \mathrm{~cm} \times 20 \mathrm{~cm}), I$ gravel matrix (120 mm depth). Not to scale

was then raised and all individuals observed above and emerging from the substrate were removed from the experimental tank. All individuals in each chamber were recaptured after the end of each trial $(100 \%$ recovery rate).

Data analysis

The proportion of $G$. pulex migrating into the sediments during drawdown was calculated and arcsine square-root transformed prior to statistical analysis. Preliminary repeated measures (RM) ANOVA tests with 'chamber' and 'trial' as betweensubject factors indicated no significant interaction between either factor and the proportion of G. pulex migrating (RM ANOVA, $P>0.05$ ). All chambers and trials were therefore pooled in subsequent $\mathrm{RM}$ ANOVA tests. RM ANOVA tests with post hoc Tukey's tests were conducted to examine differences between treatments in the proportion of G. pulex migrating by the end of each trial (i.e. when water depth was at the sediment surface). In addition, RM ANOVA tests were used to identify significant differences in the proportion of G. pulex entering the subsurface sediments as water depth was reduced for the control treatment and each FS treatment. Mauchly's tests (Mauchly, 1940) were used to verify the RM ANOVA assumption of sphericity; where this was violated, the results of Greenhouse-Geisser tests (Geisser \& Greenhouse, 1958) were consulted. Where significant migration was identified, Bonferroni pairwise comparison tests were used to determine the water depth at which this occurred. Analyses were performed using IBM SPSS Statistics (version 21, 
IBM Corporation, New York). Proportions are stated as the mean $\pm 2 \mathrm{SE}$.

\section{Results}

Effect of fine sediment treatment on Gammarus pulex migrations in response to surface water loss

The proportion of individuals migrating into the subsurface differed significantly between FS treatments (Table 1; Fig. 2). As the volume of FS increased from 0 to $20 \%$, the mean proportion of G. pulex migrating into the subsurface sediments by the end of a trial declined (Fig. 2). In the highest FS treatment (20\%), no individuals had migrated into the subsurface by the time water depth was reduced to $0 \mathrm{~mm}$. Significant differences occurred between all sediment treatments (Tukey's tests, $P<0.05$ ) with the exception of the 17.5 and $20 \%$ treatments (Tukey's tests, $P>0.05$, Fig. 2).

Effect of fine sediment volume on Gammarus pulex migrations during water drawdown

There was a significant difference in the proportion of $G$. pulex migrating into the bed during the process of water level reduction for each of the individual FS treatments, except 17.5 and $20 \%$ FS (Table 1). The point at which a significant proportion of the $G$. pulex population had migrated into the subsurface sediments differed between FS treatments. During the $0 \%$ FS (control) trial, a significant proportion

Table 1 Repeated measures analysis of variance (RM ANOVA) for the proportion of Gammarus pulex migrating into subsurface sediments in response to water drawdown $(60-0 \mathrm{~mm})$, for all and individual fine sediment treatments $(0$, $10,12.5,15,17.5$ and $20 \%$ )

\begin{tabular}{llll}
\hline Fine sediment treatment $(\%)$ & df & $F$ & $P$ \\
\hline All treatments & 5,84 & 1,643 & $<0.001$ \\
0 & 1,14 & 15,834 & $<0.001$ \\
10 & 1,14 & 4,574 & $<0.001$ \\
12.5 & 1,14 & 1,966 & $<0.001$ \\
15 & 1,14 & 2,373 & $<0.001$ \\
17.5 & 1,14 & 2.01 & $\mathrm{~ns}$ \\
20 & 1,14 & - & $\mathrm{ns}$ \\
\hline
\end{tabular}

$n s$ not significant

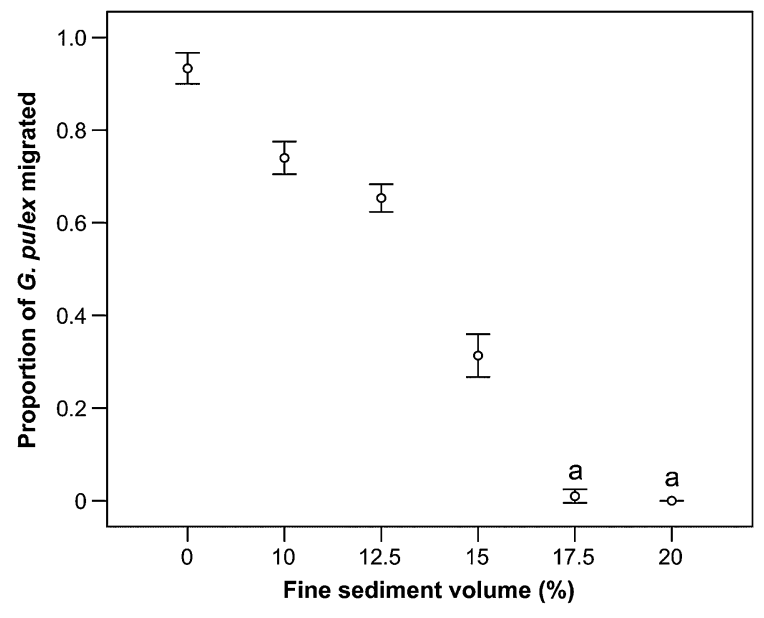

Fig. 2 Mean proportion ( $\pm 2 \mathrm{SE}$ ) of Gammarus pulex recorded migrating into the substrate following the loss of surface water (0 mm depth) in each fine sediment treatment (0-20\% interstitial volume). Letter $a$ indicates treatments which were not statistically different (Tukey's tests, $P>0.05$ )

$(26 \pm 1.4 \%)$ of $G$. pulex had actively moved into the substrate by the time water depth was reduced to $35 \mathrm{~mm}$ above the sediment surface (Bonferroni test, $P<0.05)$. The proportion migrating continued to increase steadily as water depth declined, and when depth reached $0 \mathrm{~mm}$ (i.e. the sediment surface), $93 \pm 1.7 \%$ of $G$. pulex had moved into interstitial spaces (Fig. 3a). Similarly, in the 10\% FS treatment, a significant proportion ( $24 \pm 1.9 \%)$ of the G. pulex population had entered the interstices by the time water depth was reduced to $30 \mathrm{~mm}$ (Bonferroni test, $P<0.05)$ and $74 \pm 1.8 \%$ had migrated on completion of water drawdown (Fig. $3 b$ ). In the $12.5 \%$ FS treatment, a significant proportion $(26 \pm 2.1 \%)$ of G. pulex had migrated into the interstices when water depth reached $20 \mathrm{~mm}$ (Bonferroni test, $P<0.05)$ and $65 \pm 1.5 \%$ had migrated when drawdown was complete (Fig. 3c). For the $15 \%$ FS treatment, $31 \pm 2.3 \%$ of individuals had moved into the substrate by the end of the trial, with a significant proportion migrating into the subsurface when water depth was reduced from $40 \mathrm{~mm}(14 \pm 2.1 \%)$ to $30 \mathrm{~mm} \quad(26 \pm 1.8 \%$; Bonferroni test, $P<0.05$, Fig. $3 d$ ). For the $17.5 \%$ FS treatment, $1 \pm 0.7 \%$ of G. pulex individuals had migrated into the subsurface when water depth reached $0 \mathrm{~mm}$ (Fig. 3e), and no individuals migrated into the substrate in response to water loss during the $20 \%$ FS treatment (Fig. 3f). 

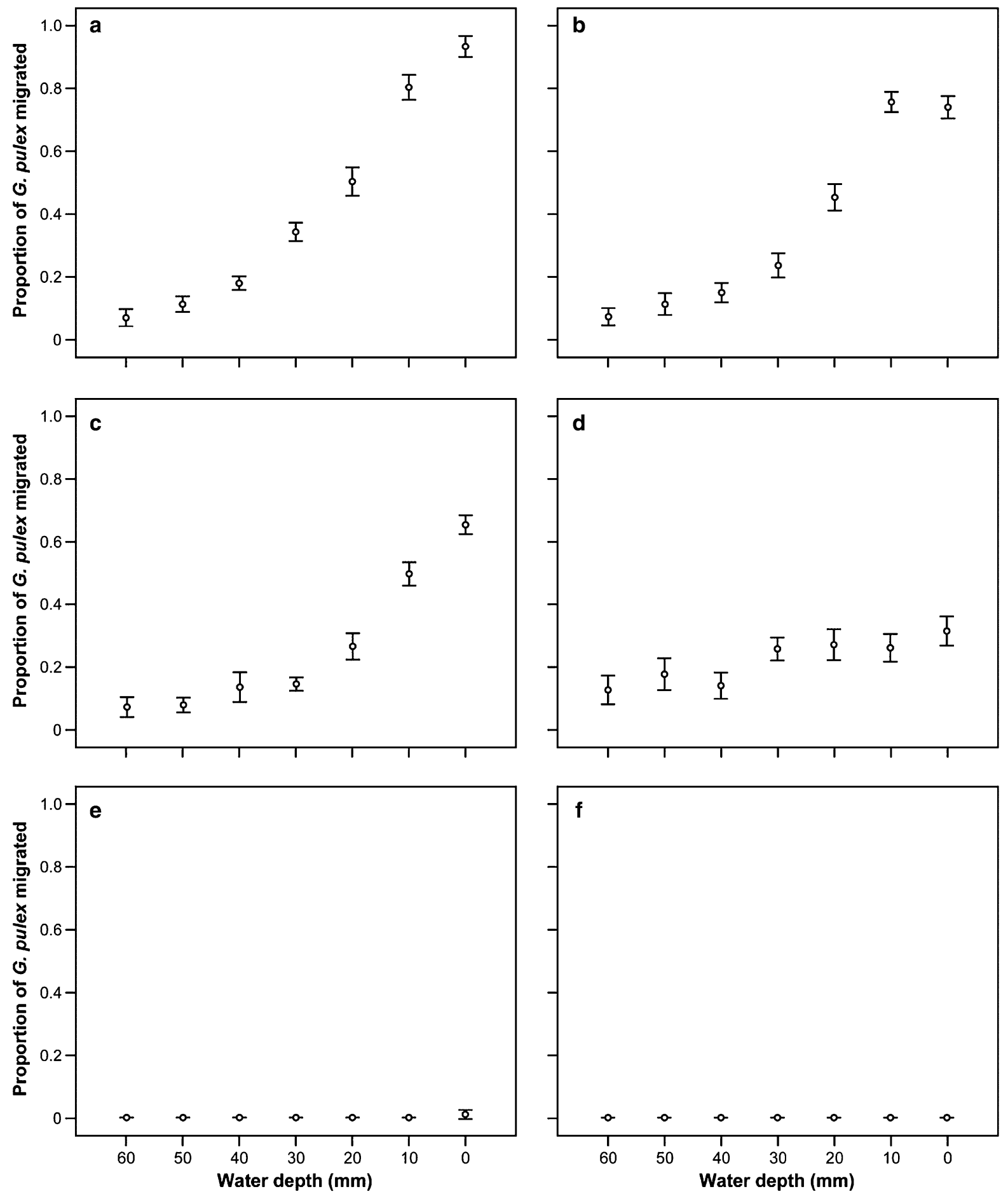

Fig. 3 Mean proportion ( $\pm 2 \mathrm{SE}$ ) of Gammarus pulex recorded migrating into the substrate during surface water drawdown in each fine sediment treatment: a $0 \%$ (control); b $10 \%$; c $12.5 \%$; d $15 \%$; e $17.5 \%$; and f $20 \%$ 


\section{Discussion}

Migration of Gammarus pulex in response to surface water loss

Previous research has found equivocal support for the hypothesis that riverbed sediments act as a refuge that promotes invertebrate persistence during instream disturbances such as streambed drying (Delucchi, 1989; Clinton et al., 1996). This equivocal evidence has been attributed to variation in environmental conditions including sediment composition (Stubbington, 2012), with fine sediment suspected to reduce refuge-seeking vertical migrations (Stanley et al., 1994; Belaidi et al., 2004). While previous studies have demonstrated that densities and interstitial movements of invertebrate taxa including Gammaridae decline as the \% of fine sediment increases (Navel et al., 2010; Descloux et al., 2013), the particle size distributions that promote and prevent vertical migrations during disturbance events remain poorly quantified. While previous research into the use of sedimentary refuges has focused on the subsurface hyporheic zone (Dole-Olivier, 2011; Stubbington, 2012), implicit within these studies is the ability of organisms to migrate through the surficial benthic zone into the contiguous subsurface sediments. We found strong evidence to support our hypothesis that increasing the volume of fine sediment within a gravel matrix would reduce and ultimately prevent $G$. pulex individuals from moving vertically into saturated interstices during drying at the sediment surface.

In our control trials ( $0 \%$ FS), most G. pulex migrated into the substrate by the time surface water was drawn down to the substrate surface. As the volume of fine sediment within the gravel matrix increased, the proportion of individuals moving into the bed during dewatering declined, while the number stranded on the substrate surface increased. These different responses to surface water loss, which are attributed to sediment characteristics, indicate why gammarids may become stranded on drying sediments (Extence, 1981; Richardson et al. 2002; Stubbington et al., 2009) despite being a mobile taxon capable of inhabiting subsurface habitats (Dole-Olivier et al., 1997; Wood et al., 2010).

We achieved our aim of identifying a threshold at which fine sediment prevented vertical migration of $G$. pulex: when the FS volume exceeded $15 \%$ of the pore space within the gravel matrix, the interstices became clogged and virtually no individuals moved below the sediment surface. However, this threshold is almost certainly specific to the FS size (1-2 mm), gravel matrix size (4-16 $\mathrm{mm}$ ) and organism size (5-12 $\mathrm{mm})$ used in this experiment. Finer sand $(<1 \mathrm{~mm}$ diameter), for example, would not bridge the gravel interstices as readily and would therefore infiltrate to greater depths (Wooster et al., 2008), potentially allowing some gammarids to enter the sediments. Equally, if the coarse matrix comprised larger gravel particles ( $>16 \mathrm{~mm}$ diameter), the pore size, shape and volume would be modified (Cui \& Parker, 1998), therefore altering the volume of fine sediment that causes clogging.

Previous studies have reported the occurrence of Gammarus spp. in sediments with higher proportions of fine sediment than those preventing migrations in our study. Descloux et al. (2013), for example, examined the effects of $10-60 \%$ FS on invertebrate assemblages, noting that Gammaridae densities declined from approximately 150-100 individuals $\mathrm{m}^{-3}$ when FS was increased from 10 to $20 \%$. However, Descloux et al. (2013) applied fine sediment to coarse sediments with a more heterogeneous particle size distribution than used in the present study. This greater substratum variability, and in particular the presence of larger particles within the matrix, may have increased the diversity and size of interstitial pathways and spaces (Wooster et al., 2008) that could be used by migrating organisms.

The wider taxonomic applicability of our results also requires consideration, since the morphology (body shape and size) and mobility (e.g. active swimming versus crawling) of taxa will influence their ability to move through interstitial spaces (Gayraud \& Philippe, 2001). Gammaridae are often among the largest macroinvertebrates in river ecosystems, and the $\%$ of fine sediment that impedes movement may, therefore, be higher for other, smaller taxa such as Chironomidae (Descloux et al., 2013). To date, few studies have examined the ability of freshwater invertebrates to move through recently deposited fine sediments (but see Wood et al., 2005; Poznańska et al., 2013). While there is evidence that sedimentation may prevent the movement of taxa including $G$. pulex within subsurface sediments (Mathers et al., 2014), other studies have demonstrated that burrowing and bioturbation activity of other taxa 
(i.e. Chironomidae: Diptera and Tubificidae: Oligochaeta) may help maintain interstitial flow paths and reduce clogging (Nogaro et al., 2006). However, such activity may be insufficient to create migration pathways for larger macroinvertebrates such as gammarids.

\section{Migration of Gammarus pulex prior to surface water loss}

During treatments of $0-15 \%$ FS, migration of the $G$. pulex population was gradual and started as soon as the reduction in water depth began. Similarly, Delucchi (1989) recorded vertical migrations of leptophlebiid mayflies and chloroperlid stoneflies prior to surface water loss from temporary stream riffles. Such behavioural responses, which also include voluntary entrance into the drift and lateral migrations, may occur following any change in hydrological conditions (Irvine, 1985; Poznańska et al., 2013) and organisms from hydrologically unstable environments may be more able to detect and respond to such changes. Stumpp \& Hose (2013), for example, found that copepod populations from a stable groundwater environment were less able to migrate in response to an experimental reduction in water level compared to those from an aquifer with a dynamic water table; the latter organisms had apparently evolved adaptations that allowed a rapid response to water level fluctuations. Further experimentation is required to determine physiological mechanisms that permit detection of such subtle hydrological stimuli.

Water depth was reduced very slowly, to minimize the possibility of water movement passively drawing members of a positively rheotactic, mobile taxon (Hughes, 1970; Elser, 2001) into the subsurface. As such, we suggest that the rapid response of G. pulex to declining water depth may be an active behavioural adaptation that allows this taxon to locate a vertical migration route in heterogeneous sediments prior to becoming stranded as surface waters recede (Extence, 1981; Stubbington et al., 2009). An early response may also allow gammarids to undertake less energetically expensive lateral migrations into remaining deeper surface waters; Poznańska et al. (2013), for example, noted that all G. fossarum individuals migrated horizontally to follow a receding water line and therefore remain submerged in experimental tanks, while only $10 \%$ burrowed vertically into sandy sediments. However, the flat substrate and lentic conditions used in our study precluded horizontal migration and voluntary drift, leaving vertical migration as the only refuge-seeking behavioural option; our study therefore represented the disconnected pool stage of the drying process in temporary streams (Lake, 2003).

Almost all G. pulex individuals remained on or above the sediment surface during preliminary trials in which water levels were held constant. This is in contrast to previous laboratory and field studies which have reported that the vertical distribution of gammarids spans the benthic and hyporheic zones. However, previous studies have encompassed biotic or physical conditions with the potential to trigger vertical migrations, for example the risk of intra- and interspecific predation (McGrath et al., 2007; Stubbington et al., 2011); the subsurface availability of leaf litter and live food resources (Mermillod-Blondin et al., 2004; Navel et al., 2010); and/or flowing water including major fluctuations in discharge (DoleOlivier et al., 1997; Stubbington et al., 2011). In the current study, conditions within the experimental facility were carefully controlled to minimize migrations in response to factors other than surface water loss. In addition, the coarse sediment size used in our investigation (4-16 $\mathrm{mm}$ gravel particles) was selected to be similar in size to the test organisms $(5-12 \mathrm{~mm})$.

Restoration and management to maximize refuge potential

Previous research has indicated that subsurface sediments provide a refuge that can promote the survival of predominantly benthic taxa during adverse instream conditions (Kawanishi et al., 2013). The availability and ecological integrity of such refuges is of increasing importance in the face of ongoing climate change, with instream communities experiencing greater frequency and duration of streambed drying as well as more frequent and intense high-flow events in some regions (Döll \& Schmied, 2012; Arnell \& Gosling, 2013). However, concurrent with this increase in instream disturbances at both hydrological extremes is an increasing prevalence of anthropogenic sedimentation (Jones et al., 2012; Extence et al., 2013). Our study highlights the negative implications of increasing fine sediment volumes for G. pulex, as it can prevent the movement of individuals into subsurface interstices, 
potentially leaving them stranded in a disturbanceimpacted habitat. The widely documented resilience of macroinvertebrate communities to hydrological disturbance is attributed to refuge availability (Lake, 2000), but key refuges may be compromised by sedimentation.

Our study highlights the importance of managing the bed sediments of perennial and temporary rivers impacted by fine sediment to maximize refuge potential, by creating and maintaining migration pathways through the benthic zone into subsurface sediments. If vertical connectivity is maintained during and after a disturbance event, subsequent community recovery and related provision of ecosystem services such as organic matter processing may be enhanced (Navel et al., 2010). River restoration by manipulation of riverbed sediments may have multiple ecological benefits, for example the addition of gravel may create fish spawning grounds as well as increasing the use of sedimentary refuges during instream disturbances (Barlaup et al., 2008). However, the success of such restoration schemes may be limited if activities are confined to the channel. Additional measures to manage fine sediment should focus on limiting catchment inputs, through the creation and maintenance of buffer strips (Owens et al., 2007) and where appropriate the re-establishment of riparian forests (Gomez et al., 2003). These measures will be essential for the long-term restoration and enhancement of effective invertebrate refuges.

Acknowledgments We are grateful for the funding and space provided by Nottingham Trent University Biosciences team to allow construction of the experimental facility. ANV acknowledges the Department of Geography at Loughborough University for technical support. We thank three anonymous reviewers for their helpful and constructive comments, which greatly improved the quality and clarity of this manuscript.

Open Access This article is distributed under the terms of the Creative Commons Attribution License which permits any use, distribution, and reproduction in any medium, provided the original author(s) and the source are credited.

\section{References}

Angradi, T. R., 1999. Fine sediment and macroinvertebrate assemblages in Appalachian streams: a field experiment with biomonitoring applications. Journal of the North American Benthological Society 18: 49-66.
Arnell, N. W. \& S. N. Gosling, 2013. The impacts of climate change on river flow regimes at the global scale. Journal of Hydrology 486: 351-364.

Barlaup, B. T., S. E. Gabrielsen, H. Skoglund \& T. Wiers, 2008. Addition of spawning gravel? A means to restore spawning habitat of Atlantic salmon (Salmo salar L.), and anadromous and resident brown trout (Salmo trutta L.) in regulated rivers. River Research and Applications 24: 543-550.

Belaidi, N., A. Taleb \& J. Gagneur, 2004. Composition and dynamics of hyporheic and surface fauna in relation to the management of a polluted reservoir. International Journal of Limnology 40: 237-248.

Boulton, A. J., M. Harvey \& H. Proctor, 2004. Of spates and species: responses by interstitial water mites to simulated spates in a subtropical Australian river. Applied and Experimental Acarology 34: 149-169.

Brunke, M., 1999. Colmation and depth filtration within streambeds: retention of particles in hyporheic interstices. International Review of Hydrobiology 84: 99-117.

Byrne, P., P. J. Wood \& I. Reid, 2012. The impairment of river systems by metal mine contamination: a review including remediation options. Critical Reviews in Environmental Science and Technology 42: 2017-2077.

Clinton, S. M., N. B. Grimm \& S. G. Fisher, 1996. Response of a hyporheic invertebrate assemblage to drying disturbance in a desert stream. Journal of the North American Benthological Society 15: 700-712.

Crane, M., 1994. Population characteristics of Gammarus pulex (L.) from five English streams. Hydrobiologia 281: 91-100.

Cui, Y. \& G. Parker, 1998. The arrested gravel front: stable gravel-sand transitions in rivers, part 2: general numerical solution. Journal of Hydraulic Research 36: 159-182.

Delucchi, C. M., 1989. Movement patterns of invertebrates in temporary and permanent streams. Oecologia 78: 199-207.

Descloux, S., T. Datry \& P. Marmonier, 2013. Benthic and hyporheic invertebrate assemblages along a gradient of increasing streambed colmation by fine sediment. Aquatic Sciences 75: 493-507.

Dole-Olivier, M.-J., 2011. The hyporheic refuge hypothesis reconsidered: a review of hydrological aspects. Marine and Freshwater Research 62: 1281-1302.

Dole-Olivier, M.-J., P. Marmonier \& J. L. Beffy, 1997. Response of invertebrates to lotic disturbance: is the hyporheic zone a patchy refugium? Freshwater Biology 37: 257-276.

Döll, P. \& H. M. Schmied, 2012. How is the impact of climate change on river flow regimes related to the impact on mean annual runoff? A global-scale analysis. Environmental Research Letters 7: 014037.

Elser, P., 2001. Assessing small-scale directional movements of benthic invertebrates in streams by using a multidirectional cage trap. Limnologica 31: 119-128.

Extence, C. A., 1981. The effect of drought on benthic invertebrate communities in a lowland river. Hydrobiologia 83: 217-224.

Extence, C. A., R. P. Chadd, J. England, M. J. Dunbar, P. J. Wood \& E. D. Taylor, 2013. The assessment of fine sediment accumulation in rivers using macro-invertebrate community response. River Research and Applications 29: $17-55$. 
Fowler, R. T. \& R. G. Death, 2001. The effect of environmental stability on hyporheic community structure. Hydrobiologia 445: 85-95.

Gayraud, S. \& M. Philippe, 2001. Does subsurface interstitial space influence general characteristics and features and morphological traits of benthic macroinvertebrate communities in streams? Archiv für Hydrobiologie 151: 667-686.

Geisser, S. \& S. W. Greenhouse, 1958. An extension of Box's results on the use of the $\mathrm{F}$ distribution in multivariate analysis. The Annals of Mathematical Statistics 29: 885-891.

Gomez, B., K. Banbury, M. Marden, N. A. Trustrum, D. H. Peacock \& P. J. Hoskin, 2003. Gully erosion and sediment production: Te Weraroa Stream, New Zealand. Water Resources Research 39: 1187.

Hughes, D. A., 1970. Some factors affecting drift and upstream movements of Gammarus pulex. Ecology 51: 301-305.

Irvine, J. R., 1985. Effects of successive flow perturbations on stream invertebrates. Canadian Journal of Fisheries and Aquatic Sciences 42: 1922-1927.

James, A. B. W., Z. S. Dewson \& R. G. Death, 2008. Do stream macroinvertebrates use instream refugia in response to short-term flow reduction in New Zealand streams? Freshwater Biology 53: 1316-1334.

Jones, J. I., J. F. Murphy, A. L. Collins, D. A. Sear, P. S. Naden \& P. D. Armitage, 2012. The impact of fine sediment on macro-invertebrates. River Research and Applications 28: 1055-1071.

Kawanishi, R., M. Inoue, R. Dohi, A. Fujii \& Y. Miyake, 2013. The role of the hyporheic zone for a benthic fish in an intermittent river: a refuge, not a graveyard. Aquatic Sciences 75: 425-431.

Kelly, D. W., J. T. A. Dick \& W. I. Montgomery, 2002. The functional role of Gammarus (Crustacea, Amphipoda): shredders, predators, or both? Hydrobiologia 485: 199-203.

Lake, P., 2000. Disturbance, patchiness, and diversity in streams. Journal of the North American Benthological Society 19: 573-592.

Lake, P. S., 2003. Ecological effects of perturbation by drought in flowing waters. Freshwater Biology 48: 1161-1172.

MacNeil, C., J. T. A. Dick \& R. W. Elwood, 1997. The trophic ecology of freshwater Gammarus spp. (Crustacea: Amphipoda): problems and perspectives concerning the functional feeding group concept. Biological Reviews 72: 349-364.

Mathers, K. L., J. Millett, A. L. Robertson, R. Stubbington \& P. J. Wood, 2014. Faunal response to benthic and hyporheic sedimentation varies with direction of vertical hydrological exchange. Freshwater Biology 59: 2278-2279.

Matthaei, C. D., F. Weller, D. W. Kelly \& C. R. Townsend, 2006. Impacts of fine sediment addition to tussock, pasture, dairy and deer farming streams in New Zealand. Freshwater Biology 51: 2154-2172.

Mauchly, J. W., 1940. Significance test for sphericity of a normal n-variate distribution. The Annals of Mathematical Statistics 11: 204-209.

McGrath, K. E., E. T. H. M. Peeters, J. A. J. Beijer \& M. Scheffer, 2007. Habitat-mediated cannibalism and microhabitat restriction in the stream invertebrate Gammarus pulex. Hydrobiologia 589: 155-164.
Mermillod-Blondin, F., J. Gaudet, M. Gerino, G. Desrosiers, J. Jose \& M. Cd Châtelliers, 2004. Relative influence of bioturbation and predation on organic matter processing in river sediments: a microcosm experiment. Freshwater Biology 49: 895-912.

Mortensen, E., 1982. Production of Gammarus pulex L. (Amphipoda) in a small Danish stream. Hydrobiologia 87: 77-97.

Navel, S., F. Mermillod-Blondin, B. Montuelle, E. Chauvet, L. Simon, C. Piscart \& P. Marmonier, 2010. Interactions between fauna and sediment control the breakdown of plant matter in river sediments. Freshwater Biology 55: 753-766.

Nerbonne, B. A. \& B. Vondracek, 2001. Effects of local land use on physical habitat, benthic macroinvertebrates, and fish in the Whitewater River, Minnesota, USA. Environmental Management 28: 87-99.

Nogaro, G., F. Mermillod-Blondin, F. François-Carcaillet, J. P. Gaudet, M. Lafont \& J. Gibert, 2006. Invertebrate bioturbation can reduce the clogging of sediment: an experimental study using infiltration sediment columns. Freshwater Biology 51: 1458-1473.

Olsen, D. A. \& C. R. Townsend, 2005. Flood effects on invertebrates, sediments and particulate organic matter in the hyporheic zone of a gravel-bed stream. Freshwater Biology 50: 839-853.

Owens, P. N., J. H. Duzant, L. K. Deeks, G. A. Wood, R. P. C. Morgan \& A. J. Collins, 2007. Evaluation of contrasting buffer features within an agricultural landscape for reducing sediment and sediment-associated phosphorus delivery to surface waters. Soil Use and Management 23: 165-175.

Perry, S. A. \& W. B. Perry, 1986. Effects of experimental flow regulation on invertebrate drift and stranding in the Flathead and Kootenai Rivers, Montana, USA. Hydrobiologia 134: 171-182.

Poznańska, M., T. Kakareko, M. Krzyżyński \& J. Kobak, 2013. Effect of substratum drying on the survival and migrations of Ponto-Caspian and native gammarids (Crustacea: Amphipoda). Hydrobiologia 700: 47-59.

Richardson, S. M., J. M. Hanson \& A. Locke, 2002. Effects of impoundment and water-level fluctuations on macrophyte and macroinvertebrate communities of a dammed tidal river. Aquatic Ecology 36: 493-510.

Sear, D. A., 1995. Morphological and sedimentological changes in a gravel-bed river following 12 years of flow regulation for hydropower. Regulated Rivers: Research \& Management 10: 247-264.

Stanley, E. H., D. L. Buschman, A. J. Boulton, N. B. Grimm \& S. G. Fisher, 1994. Invertebrate resistance and resilience to intermittency in a desert stream. American Midland Naturalist 131: 288-300.

Stubbington, R., 2012. The hyporheic zone as an invertebrate refuge: a review of variability in space, time, taxa and behaviour. Marine and Freshwater Research 63: 293-311.

Stubbington, R., A. M. Greenwood, P. J. Wood, P. D. Armitage, J. Gunn \& A. L. Robertson, 2009. The response of perennial and temporary headwater stream invertebrate communities to hydrological extremes. Hydrobiologia 630: 299-312.

Stubbington, R., P. J. Wood \& I. Reid, 2011. Spatial variability in the hyporheic zone refugium of temporary streams. Aquatic Sciences 73: 499-511. 
Stumpp, C. \& G. C. Hose, 2013. The impact of water table drawdown and drying on subterranean aquatic fauna in in vitro experiments. PLoS ONE 8: 1-10.

Weigelhofer, G. \& J. Waringer, 2003. Vertical distribution of benthic macroinvertebrates in riffles versus deep runs with differing contents of fine sediments (Weidlingbach, Austria). International Review of Hydrobiology 88: 304-313.

Williams, D. D. \& H. B. N. Hynes, 1974. The occurrence of benthos deep in the substratum of a stream. Freshwater Biology 4: 233-256.

Wood, P. J. \& P. D. Armitage, 1997. Biological effects of fine sediment in the lotic environment. Environmental Management 21: 203-217.

Wood, P. J., A. J. Boulton, S. Little \& R. Stubbington, 2010. Is the hyporheic zone a refugium for aquatic macroinvertebrates during severe low flow conditions? Fundamental and Applied Limnology 176: 377-390.

Wood, P. J., J. Toone, M. T. Greenwood \& P. D. Armitage, 2005. The response of four lotic macroinvertebrate taxa to burial by sediments. Archiv für Hydrobiologie 163: 145-162.

Wooster, J. K., S. R. Dusterhoff, Y. Cui, L. S. Sklar, W. E. Dietrich \& M. Malko, 2008. Sediment supply and relative size distribution effects on fine sediment infiltration into immobile gravels. Water Resources Research 44: 1-18.

Young, B. A., R. H. Norris \& F. Sheldon, 2011. Is the hyporheic zone a refuge for macroinvertebrates in drying perennial streams? Marine and Freshwater Research 62: 1373-1382. 